\title{
Notes on Names and Transliteration
}

In consultation with the people with whom I worked in Bahla, I have-except for scholars and political leaders-changed most people's names, as well as a few aspects of their personal lives not crucial to the analysis. I have transcribed Arabic terms using standards established by the International Journal of Middle East Studies. When transcribing from written texts, I have maintained the spellings and pronunciations of Modern Standard Arabic and, for Arabic words common in English, I have used common English spellings. I have not transliterated people's names or most place names, except neighborhoods and areas in Bahla. When transcribing words and phrases from speech I have used my discretion in suggesting Bahlawi dialect. With the exception of the epigraph in Chapter 1 (which is from an official English translation), all translations from Arabic to English throughout this book are my own. 

In the Time of Oil 
